\title{
Sleep disordered breathing, insomnia, and excessive daytime sleepiness among Japanese pregnant women without gestational complications do not negatively impact delivery outcomes
}

Hideaki Kondo ( $\nabla$ kondo.hideaki.gb@u.tsukuba.ac.jp )

International Institute for Integrative Sleep Medicine, The University of Tsukuba https://orcid.org/00000003-0856-6650

Shiho Umeno

Karatsu Red Cross Hospital

Hiromi Eto

Nagasaki University

Chiho Kato

Japan Red Cross College of Nursing

Yuki Nagaura

Nagasaki University

Research article

Keywords: excessive daytime sleepiness, insomnia, sleep disordered breathing, sleep quality, restless legs syndrome/Willis-Ekbom disease

Posted Date: November 11th, 2019

DOI: https://doi.org/10.21203/rs.2.17103/v1

License: (c) (i) This work is licensed under a Creative Commons Attribution 4.0 International License. Read Full License 


\section{Abstract}

Frequently observed sleep/wake problems among pregnant women need comprehensive evaluation. This study was conducted to clarify the sleep/wake problems among pregnant women without gestational complications at the second and third trimester and the effects of sleep/wake problems on delivery outcomes. Methods: A total of 88 Japanese pregnant women participated in this study. At the second and third trimester, subjective sleep quality, insomnia severity, excessive daytime sleepiness (EDS), and restless legs syndrome/Willis-Ekbom disease (RLS/WED) were assessed using questionnaires; also, sleep disordered breathing (SDB) was screened using a pulse oximeter. Results: From the second to third trimester, an increasing tendency of sleep/wake problems was observed. At the third trimester, the percentage of women experiencing decreased subjective sleep quality, difficulty maintaining sleep (DMS), EDS, RLS/WED, and $3 \%$ oxygen desaturation index (ODI) values $\geq 5 / \mathrm{h}$ were $62.5 \%, 45.5 \%, 48.9 \%, 9.1 \%$, and $29.5 \%$, respectively. In a logistic regression analysis for EDS at the third trimester, the adjusted odds ratio ( $95 \%$ confidence interval) of total sleep time $<6$ hours, moderate to severe DMS, and $3 \%$ ODI $\geq 5 / h$ were 3.25 (1.16-9.10), 4.74 (1.60-14.00), and 0.90 (0.28-2.89), respectively. Decreased subjective sleep quality, insomnia severity, EDS, and SDB did not affect the delivery outcome or infant's condition. Conclusions: Sleep/wake problems were frequent during pregnancy, especially at the third trimester. EDS among pregnant women was associated with shorter sleep time and DMS, rather than SDB. However, there were no significant effects of sleep/wake problems on the delivery outcomes or infant's conditions.

\section{Background}

Sleep disordered breathing (SDB), frequent among pregnant women, is associated with gestational diabetes and hypertensive disorders during pregnancy [1-3]. Also, maternal SDB affects delivery outcomes and is associated with preterm birth and admission to the neonatal intensive care unit $[1,4,5]$. The prevalence of SDB increases during the course of pregnancy and a meta-analysis reported a prevalence of $15 \%$ (95\% confidence interval [Cl]: 12-18\%) [1]. In a study using polysomnography (PSG), the prevalence of an apnea-hypopnea index (AHI) value $\geq 5 / \mathrm{h}$ at the first and third trimester, after adjusting for the general body mass index (BMI) of pregnant women, were $8.4 \%$ and $19.7 \%$, respectively [6]. Among high-risk pregnant women with a $B M I \geq 30 \mathrm{~kg} / \mathrm{m}^{2}$, the prevalence of an $A H I \geq 5 / \mathrm{h}$ at the first and third trimester is reported as $30 \%$ and $47 \%$, respectively [7].

In previous studies performed in Europe and the US, about half of the participants' pre-pregnancy BMI values were greater than or equal to $25 \mathrm{~kg} / \mathrm{m}^{2}[4,5,2,3,6,7]$. In a study performed in Japan, the mean \pm standard deviation (SD) of the participants' pre-pregnancy BMI value was $23.8 \pm 6.1 \mathrm{~kg} / \mathrm{m}^{2}$, and the prevalence of having a $3 \%$ oxygen desaturation index (ODI) value $\geq 5 / \mathrm{h}$ was $12.3 \%$ after 28 weeks gestation. This group was associated with a history of spontaneous abortion, emergency cesarean birth, and vacuum extraction [8]. Among pregnant women without gestational complications, whose prepregnancy BMI values were $22.2 \pm 2.6 \mathrm{~kg} / \mathrm{m}^{2}$, none had a $3 \% \mathrm{ODI} \geq 5 / \mathrm{h}$ at the second trimester [9]. The prevalence of SDB among Japanese pregnant women vary greatly. 
During pregnancy, increased waking after sleep onset and decreased sleep efficiency are frequently observed [10,11], and complaints about insomnia symptoms are prevalent [12]. Also, a decrease in subjective sleep quality is often observed [13] and restless legs syndrome/Willis-Ekbom disease (RLS/WED), related to insomnia and decreased sleep quality, is also prevalent [14]. Moreover, complaints about excessive daytime sleepiness (EDS) are common among pregnant women [15]. Although EDS is affected by SDB, insomnia and/or sleep insufficiency also influence EDS. To clarify the cause of EDS, sleep related problems must be evaluated comprehensively. This study aims to clarify the sleep/wake problems among pregnant Japanese women without gestational complications at the second and third trimester of pregnancy and the effects of sleep/wake problems on delivery outcomes.

\section{Methods}

\section{Participants and protocol}

The participants were pregnant women who were undergoing pregnancy-related medical examinations at an obstetric medical facility in Nagasaki Prefecture from December 2017 until October 2018. Women who had pregnancy complications were excluded. A total of 143 pregnant women were asked to participate in the study and 113 women consented to participate in this research at their second trimester of pregnancy (around 24 weeks gestation). After accounting for women who dropped out due to obstetric or experienced technological issues related to data collection during the study period, effective responses were obtained from 107 women $(74.8 \%)$ in the second trimester and $88(61.5 \%)$ in the third trimester (around 37 weeks gestation). The final analysis was performed among 88 participants (Figure 1).

Participants were aged between 19 and 42 years old, with a mean age ( \pm SD) of $30.9 \pm 4.7$ years. Forty women were primipara ( $46 \%)$. The data were collected at $24.6 \pm 0.6$ weeks gestation in the second trimester and $36.2 \pm 0.9$ weeks gestation in the third trimester. The median (interquartile range [IQR]) prepregnancy BMI was $20.3(18.9-22.1) \mathrm{kg} / \mathrm{m}^{2}$ and 6 women (6.9\%) were obese (BMl $\geq 25 \mathrm{~kg} / \mathrm{m} 2$ ).

All procedures performed this study involving human participants were in accordance with the ethical standards of the institutional and/or national research committee and with the 1964 Helsinki declaration and its later amendments or comparable ethical standards. This study was approved by the Ethics Committee of Nagasaki University Graduate School of Biomedical Sciences (Approval No. 1711090). Informed consent was obtained from all individual participants included in the study.

We obtained demographic and clinical characteristics of all participants including age, body weight (prepregnancy, second trimester, and third trimester), height, history of gravidity, history of parity. Prepregnancy, second trimester, and third trimester BMls were calculated. The delivery and neonatal information were collected from midwifery records including gestational age, duration of birth, type of birth (vaginal delivery, cesarean section), labor induction, episiotomy, perineal laceration, uterus contraction, oxytocic agent use, volume of blood loss, the infant's condition, infant weight, infant height, Apgar score, umbilical pH, and umbilical partial pressure of carbon dioxide. Self-reported questionnaires 
related to sleep/wake problems were administered and SDB screening was performed over 2 consecutive nights using a pulse oximeter during the second and third trimester.

\section{Pulse oximeter}

SDB was screened using a pulse oximeter (PULSOX-300i, KONICA MINOLTA Japan, Inc., Tokyo, Japan). The pulse oximeter was attached to the first joint of the second or third fingers on the non-dominant hand at bedtime and removed at the time of awakening over 2 consecutive nights. The data were downloaded to a personal computer using DS-Me version 2.1 (KONICA MINOLTA Japan, Inc.). After removing poor measurement periods, the $3 \%$ ODI was calculated, defined as the number of times per hour in which the oxygen saturation decreased by $3 \%$ or more from the baseline. Patients who had a $3 \%$ ODI $\geq 5$ were defined as having suspected SDB [8].

\section{Questionnaires}

\section{Pittsburgh Sleep Quality Index}

Subjective sleep quality was assessed using the Japanese version of the Pittsburgh Sleep Quality Index (PSQI). This questionnaire consists of 7 components including sleep quality, sleep latency, sleep duration, sleep efficiency, sleep disturbance, hypnotic use, and daytime dysfunction. The score of each component ranges from 0 to 3 , with global scores ranging from 0 to 21 . Higher scores indicate inadequate sleep quality with scores $\geq 6$ indicating poor sleep quality $[16,17]$. ; therefore, women with global scores $\geq 6$ were categorized into a "poor sleeper" group. According to a meta-analysis, the sensitivity and specificity $(95 \% \mathrm{Cl})$ for insomnia are $0.94(0.86-0.98)$ and $0.76(0.64-0.85)$, respectively [18].

\section{Insomnia Severity Index}

Insomnia severity was assessed using the Japanese version of the Insomnia Severity Index (ISI). The severity of difficulty initiating sleep (DIS) and difficulty maintaining sleep (DMS) are answered as "none", "mild", "moderate", "severe", or "very severe". Responders who had "mild" to "very severe" symptoms were defined as having DIS and DMS. Responders who had "moderate" to "very severe" symptoms were defined as having moderate to severe DIS and DMS. The global score of this index ranges from 0 to 28 , with higher scores indicating greater insomnia severity, and the cut off score for insomnia is 10 points [19]. According to a meta-analysis, the sensitivity and specificity $(95 \% \mathrm{Cl})$ for insomnia is $0.88(0.79-$ $0.93)$ and $0.85(0.68-0.94)$, respectively [18]. 


\section{Epworth Sleepiness Scale}

Daytime sleepiness was assessed using the Japanese version of the Epworth Sleepiness Scale (ESS). The global score on this scale ranges from 0 to 24, with higher scores indicating greater subjective daytime sleepiness and the cut off score for EDS is 10 points [20,21]. In this study, we categorized participants with an ESS score $\geq 11$ as the EDS group, because a daytime dysfunction score $\geq 2$ on the PSQI, which reflects daytime sleepiness, was associated with an ESS score $\geq 11$, not an ESS score $\geq 10$.

\section{Cambridge-Hopkins Questionnaire Short Form13}

Symptoms related to RLS/WED were assessed using the Japanese version of the Cambridge-Hopkins questionnaire short form 13 (CH-RLSq13). The $\mathrm{CH}-\mathrm{RLSq} 13$ is a self-reported questionnaire containing 13 items, 10 of which are related to characteristic symptoms and the exclusion of other conditions (e.g., leg cramping and positional discomfort); the remaining 3 items are related symptom severity and onset. The sensitivity and specificity of the original CH-RLSq13 for an RLS/WED diagnosis have been reported as $87.2 \%$ and $94.4 \%$, respectively, and those of the Japanese version are $88.9 \%$ and $100.0 \%$, respectively [22].

\section{Statistical analysis}

R version 3.5.2 and EZR version 1.40 (http://www.jichi.ac.jp/saitama-sct/SaitamaHP.files/statmed.html) [23] were used for statistical analysis. Categorical variables were presented as counts and percentages. Continuous variables were presented as the mean and SD when normally distributed and as medians and IQRs when non-normally distributed. Comparisons were made using t-tests for normally distributed data and Mann-Whitney $U$ tests for non-normally distributed data. Comparisons of continuous variables between the second and third trimester were performed using the Wilcoxon signed-rank test. Frequency analyses for categorical data were performed using a Fisher's exact test. Frequency analyses between the second and third trimester were performed using a McNemar's test. The 2-sided alpha level was set at 0.05 .

The odds ratios for EDS were calculated using logistic regression analysis to assess the association with total sleep time, DMS, and SDB. After a univariate analysis, adjustments for age and BMI were made. Age and BMI were categorized into 2 groups each: age $<30$ years (reference) or $\geq 30$ years and $\mathrm{BMI}<25$ $\mathrm{kg} / \mathrm{m} 2$ (reference) or $\geq 25 \mathrm{~kg} / \mathrm{m} 2$. Total sleep time obtained from the PSQI was categorized into 2 groups: < 6 hours and $\geq 6$ hours (reference). DMS was categorized into 2 groups: none-mild (reference) and moderate-severe. Also, 3\% ODI values were categorized into 2 groups: $<5 / h$ (reference) and $\geq 5 / h$.

\section{Results}


The percentage of women in the poor sleeper group increased from $34.1 \%$ in the second trimester to $62.5 \%$ in the third trimester $(p<0.001)$. More than $90 \%$ of women had DIS and DMS at the third trimester and the percentage of women having moderate to severe DIS and DMS increased from $31.8 \%$ in the second trimester to $55.7 \%$ in the third trimester $(p<0.001)$. Although the percentage of women having EDS (ESS $\geq 11$ ) did not show significant changes from the second to third trimester, almost half of the participants were aware of EDS during their pregnancy. The percentage of women having RLS/WED increased from $2.3 \%$ to $9.1 \%(p=0.04$, Table 1$)$.

Although, the percentage of women in the SDB group, which were those with a $3 \%$ ODI $\geq 5 / h$, showed an increasing tendency with values of $18.2 \%$ in the second trimester to $29.5 \%$ in the third trimester; there was no statistically significant increase $(p=0.08)$. There was no suspected moderate to severe SDB, defined with a $3 \% O D I \geq 15 / h$, at the second trimester, and only 1 participant had a $3 \% O D I \geq 15 / h$ at the third trimester (Table 1). The median BMIs of the $3 \%$ ODI $\geq 5 / \mathrm{h}$ group at the third trimester were higher than those in the $3 \% \mathrm{ODI}<5 / \mathrm{h}$ group from pre-pregnancy to the third trimester (Table 2). DMS was frequent in the $3 \% \mathrm{ODI}<5 / \mathrm{h}$ group at the third trimester. However, an association with SDB and EDS was not found (Table 3).

In the ESS $\geq 11$ group at the third trimester, decreased subjective sleep quality, shorter sleep time, and moderate to severe DMS was found; also, ISI global scores in this group were $\geq 10$ (Table 4). In a logistic regression analysis for EDS at the third trimester, the adjusted odds ratio $(95 \% \mathrm{Cl})$ of total sleep time $<6$ hours, moderate to severe DMS, and $3 \% \mathrm{ODI} \geq 5 / \mathrm{h}$ were 3.25 (1.16-9.10), 4.74 (1.60-14.00), and 0.90 (0.28-2.89), respectively (Table 5$)$. There was no collinearity between total sleep time and DMS. The median (IQR) total sleep time among participants with ISI values $\geq 10$ was significantly shorter than those with ISI values < 10: $6.50(6.00-7.75)$ hours vs. $7.00(7.00-8.00)$ hours $(p=0.02)$.

Compared to the $3 \% \mathrm{ODI}<5 / \mathrm{h}$ group, there was no significant effect on delivery outcomes or infant conditions in the $3 \% \mathrm{ODI} \geq 5 / \mathrm{h}$ group (Table 6). Similarly, decreased subjective sleep quality, insomnia severity, and EDS did not affect delivery outcomes or the infant's condition (Supplementary Tables 1-3).

\section{Discussion}

\section{Excessive daytime sleepiness among pregnant women}

In this study, SDB was not a significant factor for EDS among pregnant women. It has been reported that ESS global scores at pre-pregnancy and the third trimester among pregnant women who are obese are higher than those without are not obese [24]. Moreover, snoring during the first trimester is associated with not only continuous EDS throughout pregnancy, but also with EDS onset during pregnancy [15]. In the present study, there were only 6 pre-pregnancy obese participants and almost all suspected SDB participants were thought to be mild cases. These factors might influence the relationship between SDB and EDS. 
Although, DIS and DMS at the third trimester were frequently observed in the present study, moderate to severe DMS, rather than moderate to severe DIS, affected EDS. In some previous studies, DMS was more frequent than DIS. In objective findings using PSG during pregnancy, significant prolongation of sleep latency was been observed and increased wake time after sleep onset and decreased sleep efficiency was reported $[10,11]$. Furthermore, while the percentage of DIS was only $14 \%$, the percentage of DMS was as high as $70 \%$ in the subjective findings using a Basic Nordic Sleep Questionnaire at the third trimester [25]. The discrepancy in insomnia symptom frequency might be caused by the differences between questionnaires or the severity of insomnia symptoms. Also, the study using PSG has had a small sample size, so this approach needs to be evaluated on a larger scale.

RLS/WED is prevalent among pregnant women and it affect DIS, DMS, and EDS [14,26,27]. In the present study, the prevalence of suspected RLS/WED was increased at the third trimester. However, the presence of RLS/WED did not affect EDS, insomnia symptoms, or subjective sleep quality. In Japanese pregnant women without gestational complications, few severe cases of RLS/WED were reported, and almost all RLS/WED patients reported mild to moderate issues [28]. Among 8 suspected RLS/WED patients at the third trimester of pregnancy in this study, 7 indicated they had moderate to severe symptoms. However, only 3 patients experienced these symptoms twice a week or more. The lower symptom occurrence frequency and the small sample size might influence the relationship between RLS/WED and EDS.

In the present study, a short sleep time of $<6$ hours was associated with EDS. Total sleep time among participants with insomnia was shorter than those without insomnia. Although there was no collinearity between total sleep time and DMS in a logistic regression analysis, a shorter sleep time induced by DMS, but might affect EDS.

\section{Sleep disordered breathing among pregnant women}

In the present study, BMI values among pregnant women with a $3 \% \mathrm{ODI} \geq 5 / \mathrm{h}$ were higher than those with a $3 \% \mathrm{ODI}<5 / \mathrm{h}$ from pre-pregnancy to the third trimester; the tendency was clearly noticeable in the later period of pregnancy. However, there were few participants with obesity in this study. Also, a lower $\mathrm{BMI}$ is thought to be associated with a lower desaturation index obtained from the pulse oximeter.

SDB is associated with gestational complications, delivery outcomes, and neonatal conditions $[1,4,5,2,3]$. However, there was no significant effect on delivery outcomes and infant conditions in the $3 \% O D I \geq 5 / h$ group. Overall, SDB severity was relatively mild in the study participants; this is thought to contribute to the good outcomes along with the fact that the participants had no gestational complications.

\section{Limitations}


The present study possesses some limitations of note. First, the results did not reflect the conditions of all pregnant women since they were obtained from Japanese women without gestational complications. Hence, we could not assess the sleep/wake problems among high risk pregnant women also suffering from obesity. Second, SDB was evaluated using only a pulse oximeter; therefore, the information on sleep stages, respiration itself, and position were lacking in this study. Third, symptoms of RLS/WED were examined using a self-reported questionnaire; thus a diagnosis of RLS/WED was not confirmed by sleep medicine specialists.

\section{Conclusions}

From the second to third trimester, an increasing tendency of sleep/wake problems was observed. However, there were few pregnant women with moderate to severe SDB and there were no significant effects of SDB on the delivery outcome and infant's condition. Also, EDS among pregnant women was associated with a shorter sleep time and DMS, rather than SDB. Consequently, sleep hygiene awareness including sleep duration and insomnia among Japanese pregnant women without gestational complications is needed. To further evaluate the effects of sleep/wake disorders on gestational complications and delivery outcomes, additional research is needed, beginning from pre-pregnancy, on a large scale including high-risk pregnant women.

\section{Abbreviations}

AHI: apnea-hypopnea index

BMI: body mass index

Cl: confidence interval

CH-RLSq13: Cambridge-Hopkins questionnaire short form 13

DIS: difficulty initiating sleep

DMS: difficulty maintaining sleep

EDS: excessive daytime sleepiness

ESS: Epworth Sleepiness Scale

IQR: interquartile range

ISI: Insomnia Severity Index

ODI: oxygen desaturation index

PSQI: Pittsburgh Sleep Quality Index 
RLS/WED: restless legs syndrome/Willis-Ekbom disease

SD: standard deviation

SDB: sleep disordered breathing

\section{Declarations}

Ethics approval and consent to participate: All procedures performed in studies involving human participants were in accordance with the ethical standards of the institutional and/or national research committee and with the 1964 Helsinki declaration and its later amendments or comparable ethical standards. This study was approved by the Ethics Committee of Nagasaki University Graduate School of Biomedical Sciences (Approval No. 1711090). Informed consent was obtained from all individual participants included in the study.

Consent for publication: Not applicable.

Availability of data and materials: All data generated or analysed during this study are included in this published article and its supplementary information files.

Competing interests: The authors declare that they have no competing interest.

Funding: This work was supported by JSPS KAKENHI Grant Number JP16X15931.

Authors' contributions: $\mathrm{CK}, \mathrm{HE}, \mathrm{YN}$, and $\mathrm{HK}$ designed the data collection. SU interviewed and enrolled eligible participants and completed all study procedures. EH drafted the initial manuscript. All authors read and approved the final manuscript.

Acknowledgements: We thank the pregnant women for their participation in our study.

\section{References}

1. Liu L, Su G, Wang S, Zhu B (2019) The prevalence of obstructive sleep apnea and its association with pregnancy-related health outcomes: a systematic review and meta-analysis. Sleep Breath 23 (2):399-412. doi:10.1007/s11325-018-1714-7

2. Dominguez JE, Habib AS, Krystal AD (2018) A review of the associations between obstructive sleep apnea and hypertensive disorders of pregnancy and possible mechanisms of disease. Sleep medicine reviews 42:37-46. doi:10.1016/j.smrv.2018.05.004

3. Facco FL, Parker CB, Reddy UM, Silver RM, Koch MA, Louis JM, Basner RC, Chung JH, Nhan-Chang CL, Pien GW, Redline S, Grobman WA, Wing DA, Simhan HN, Haas DM, Mercer BM, Parry S, Mobley D, Hunter S, Saade GR, Schubert FP, Zee PC (2017) Association Between Sleep-Disordered Breathing and Hypertensive Disorders of Pregnancy and Gestational Diabetes Mellitus. Obstetrics and gynecology 129 (1):31-41. doi:10.1097/aog.0000000000001805 
4. Warland J, Dorrian J, Morrison JL, O'Brien LM (2018) Maternal sleep during pregnancy and poor fetal outcomes: A scoping review of the literature with meta-analysis. Sleep medicine reviews 41:197-219. doi:10.1016/j.smrv.2018.03.004

5. Li L, Zhao K, Hua J, Li S (2018) Association between Sleep-Disordered Breathing during Pregnancy and Maternal and Fetal Outcomes: An Updated Systematic Review and Meta-Analysis. Frontiers in neurology 9:91. doi:10.3389/fneur.2018.00091

6. Pien GW, Pack Al, Jackson N, Maislin G, Macones GA, Schwab RJ (2014) Risk factors for sleepdisordered breathing in pregnancy. Thorax 69 (4):371-377. doi:10.1136/thoraxjnl-2012-202718

7. Facco FL, Ouyang DW, Zee PC, Grobman WA (2014) Sleep disordered breathing in a high-risk cohort prevalence and severity across pregnancy. American journal of perinatology 31 (10):899-904. doi:10.1055/s-0033-1363768

8. Miyagawa S, Emori Y, Kawano A, Sakurai S, Tanigawa T (2011) Relationship between sleepdisordered breathing and perinatal outcome in pregnant women. J Jpn Acad Midwif 25 (1):5-12

9. Watanabe $\mathrm{M}$, Shinohara $\mathrm{H}$, Kodama $\mathrm{H}$ (2015) Impact of overnight oximetry findings on cardiac autonomic modulation in women during second trimester of uncomplicated pregnancy. J Obstet Gynaecol Res 41 (5):689-696. doi:10.1111/jog.12634

10. Wilson DL, Barnes M, Ellett L, Permezel M, Jackson M, Crowe SF (2011) Decreased sleep efficiency, increased wake after sleep onset and increased cortical arousals in late pregnancy. The Australian \& New Zealand journal of obstetrics \& gynaecology 51 (1):38-46. doi:10.1111/j.1479828X.2010.01252.x

11. Hertz G, Fast A, Feinsilver SH, Albertario CL, Schulman H, Fein AM (1992) Sleep in normal late pregnancy. Sleep 15 (3):246-251. doi:10.1093/sleep/15.3.246

12. Hashmi AM, Bhatia SK, Bhatia SK, Khawaja IS (2016) Insomnia during pregnancy: Diagnosis and Rational Interventions. Pak J Med Sci 32 (4):1030-1037. doi:10.12669/pjms.324.10421

13. Sharma SK, Nehra A, Sinha S, Soneja M, Sunesh K, Sreenivas V, Vedita D (2016) Sleep disorders in pregnancy and their association with pregnancy outcomes: a prospective observational study. Sleep Breath 20 (1):87-93. doi:10.1007/s11325-015-1188-9

14. Chen SJ, Shi L, Bao YP, Sun YK, Lin X, Que JY, Vitiello MV, Zhou YX, Wang YQ, Lu L (2018) Prevalence of restless legs syndrome during pregnancy: A systematic review and meta-analysis. Sleep medicine reviews 40:43-54. doi:10.1016/j.smrv.2017.10.003

15. Tsai SY, Lee PL, Lin JW, Lee CN (2017) Persistent and new-onset daytime sleepiness in pregnant women: A prospective observational cohort study. Int J Nurs Stud 66:1-6. doi:10.1016/j.ijnurstu.2016.11.003

16. Doi Y, Minowa M, Uchiyama M, Okawa M, Kim K, Shibui K, Kamei Y (2000) Psychometric assessment of subjective sleep quality using the Japanese version of the Pittsburgh Sleep Quality Index (PSQI-J) in psychiatric disordered and control subjects. Psychiatry Res 97 (2-3):165-172

17. Buysse DJ, Reynolds CF, 3rd, Monk TH, Berman SR, Kupfer DJ (1989) The Pittsburgh Sleep Quality Index: a new instrument for psychiatric practice and research. Psychiatry Res 28 (2):193-213. 
doi:0165-1781(89)90047-4 [pii]

18. Chiu HY, Chang LY, Hsieh YJ, Tsai PS (2016) A meta-analysis of diagnostic accuracy of three screening tools for insomnia. J Psychosom Res 87:85-92. doi:10.1016/j.jpsychores.2016.06.010

19. Bastien CH, Vallieres A, Morin CM (2001) Validation of the Insomnia Severity Index as an outcome measure for insomnia research. Sleep Med 2 (4):297-307

20. Takegami M, Suzukamo Y, Wakita T, Noguchi H, Chin K, Kadotani H, Inoue Y, Oka Y, Nakamura T, Green J, Johns MW, Fukuhara S (2009) Development of a Japanese version of the Epworth Sleepiness Scale (JESS) based on item response theory. Sleep Med 10 (5):556-565. doi:S13899457(08)00184-6 [pii]10.1016/j.sleep.2008.04.015

21. Johns M, Hocking B (1997) Daytime sleepiness and sleep habits of Australian workers. Sleep 20 (10):844-849. doi:10.1093/sleep/20.10.844

22. Allen RP, Burchell BJ, MacDonald B, Hening WA, Earley CJ (2009) Validation of the self-completed Cambridge-Hopkins questionnaire (CH-RLSq) for ascertainment of restless legs syndrome (RLS) in a population survey. Sleep Med 10 (10):1097-1100. doi:10.1016/j.sleep.2008.10.007

23. Kanda Y (2013) Investigation of the freely available easy-to-use software 'EZR' for medical statistics. Bone marrow transplantation 48 (3):452-458. doi:10.1038/bmt.2012.244

24. Amador-Licona N, Guizar-Mendoza JM (2012) Daytime sleepiness and quality of life: are they associated in obese pregnant women? Archives of gynecology and obstetrics 285 (1):105-109. doi:10.1007/s00404-011-1879-9

25. Polo-Kantola P, Aukia L, Karlsson H, Karlsson L, Paavonen EJ (2017) Sleep quality during pregnancy: associations with depressive and anxiety symptoms. Acta Obstet Gynecol Scand 96 (2):198-206. doi:10.1111/aogs.13056

26. Dunietz GL, Lisabeth LD, Shedden K, Shamim-Uzzaman QA, Bullough AS, Chames MC, Bowden MF, O'Brien LM (2017) Restless Legs Syndrome and Sleep-Wake Disturbances in Pregnancy. Journal of clinical sleep medicine : JCSM : official publication of the American Academy of Sleep Medicine 13 (7):863-870. doi:10.5664/jcsm.6654

27. Picchietti DL, Hensley JG, Bainbridge JL, Lee KA, Manconi M, McGregor JA, Silver RM, Trenkwalder C, Walters AS (2015) Consensus clinical practice guidelines for the diagnosis and treatment of restless legs syndrome/Willis-Ekbom disease during pregnancy and lactation. Sleep medicine reviews 22:6477. doi:10.1016/j.smrv.2014.10.009

28. Hatanaka A, Eto H, Kato C, Yamaguchi Y, Sakamoto H, Kondo H (2017) Prevalence and clinical features of restless legs syndrome among Japanese pregnant women without gestational complications. Sleep and Biological Rhythms 15 (2):183-186. doi:10.1007/s41105-016-0086-2

\section{Tables}

Table 1. Comparison of body weight and sleep problems during the second and third trimester of pregnancy $(\mathrm{N}=$ 88) 


\begin{tabular}{|c|c|c|c|}
\hline & Second trimester & Third trimester & $\mathrm{p}$ value \\
\hline Body mass index kg/m2, median (IQR) & $22.6(21.3-24.3)$ & $24.2(22.5-26.3)$ & $<0.001$ \\
\hline Weight gain ${ }^{1)} \mathrm{kg}$, median (IQR & $6.4(4.8-8.1)$ & $10.2(8.5-13.3)$ & $<0.001$ \\
\hline Rate of weight gain* \%, median (IQR) & $11.5(7.7-13.9)$ & $19.0(14.9-22.6)$ & $<0.001$ \\
\hline \multicolumn{4}{|l|}{ PSQI } \\
\hline C1】sleep quality $\geq 2, \mathrm{n}(\%)$ & $25(28.4)$ & $51(58.0)$ & $<0.001$ \\
\hline C2ロsleep latency $\geq 2^{2)}, \mathrm{n}(\%)$ & $26(29.5)$ & $43(48.9)$ & 0.003 \\
\hline C3ロsleep duration $\geq 2^{3)}, \mathrm{n}(\%)$ & $23(26.1)$ & $30(34.1)$ & $<0.001$ \\
\hline C4【sleep efficiency $\geq 2^{4)}, \mathrm{n}(\%)$ & $5(5.7)$ & $12(13.6)$ & 0.10 \\
\hline C5 $\square$ sleep disturbance $\geq 2, \mathrm{n}(\%)$ & $23(26.1)$ & $49(55.7)$ & $<0.001$ \\
\hline C6ロhypnotic use $\geq 2^{5)}, \mathrm{n}(\%)$ & $0(0.0)$ & $1(1.1)$ & $<0.001$ \\
\hline C7ロdaytime dysfunction $\geq 2, \mathrm{n}(\%)$ & $8(9.1)$ & $8(9.1)$ & 0.64 \\
\hline Global score $\geq 6, \mathrm{n}(\%)$ & $30(34.1)$ & $55(62.5)$ & $<0.001$ \\
\hline \multicolumn{4}{|l|}{ ISI } \\
\hline Mild to severe DIS, n (\%) & $36(40.9)$ & $71(80.7)$ & $<0.001$ \\
\hline Moderate to severe DIS, n (\%) & $16(18.2)$ & $37(42.0)$ & $<0.001$ \\
\hline Mild to severe DMS, n (\%) & $52(59.1)$ & $67(76.1)$ & 0.007 \\
\hline Moderate to severe DMS, n (\%) & $23(26.1)$ & $40(45.5)$ & 0.005 \\
\hline Mild to severe DIMS, n (\%) & $57(64.8)$ & $80(90.9)$ & $<0.001$ \\
\hline Moderate to severe DIMS, $\mathrm{n}(\%)$ & $28(31.8)$ & $49(55.7)$ & $<0.001$ \\
\hline Global score $\geq 10, \mathrm{n}(\%)$ & $18(20.5)$ & $47(53.4)$ & $<0.001$ \\
\hline $\mathrm{ESS} \geq 10, \mathrm{n}(\%)$ & $46(52.3)$ & $47(53.4)$ & 1 \\
\hline $\mathrm{ESS} \geq 11, \mathrm{n}(\%)$ & $39(44.3)$ & $43(48.9)$ & 0.48 \\
\hline RLS/WED, n (\%) & $2(2.3)$ & $8(9.1)$ & 0.04 \\
\hline $3 \%$ ODI $\geq 5 / h, n(\%)$ & $16(18.2)$ & $26(29.5)$ & 0.08 \\
\hline $5 \leq 3 \%$ ODI $<15 / \mathrm{h}, \mathrm{n}(\%)$ & $16(18.2)$ & $25(28.4)$ & \\
\hline $3 \%$ ODI $\geq 15 / h, n(\%)$ & $0(0.0)$ & $1(1.1)$ & \\
\hline
\end{tabular}

1) From pre-pregnancy. ${ }^{2)}$ Sleep latency $\geq 31$ min and the presence of difficulty initiating sleep. ${ }^{3)}$ Total sleep time $<6$ hours. ${ }^{4)}$ Sleep Efficiency <85\%. ${ }^{5)}$ More than one time. DIS, difficulty initiating sleep; DISM, difficulty initiating and/or maintaining sleep; DMS, difficulty maintaining sleep; ESS, Epworth Sleepiness Scale; ISI, Insomnia Severity Index; IQR, interquartile range; ODI, oxygen desaturation index; PSQI, Pittsburgh Sleep Quality Index global score; RLS/WED, restless legs syndrome/Willis-Ekbom disease.

Table 2. Comparison of clinical characteristics between 3\% ODI $<5 /$ hroup and 3\% ODI $\geq 5 /$ h group at the third trimester of pregnancy 


\begin{tabular}{|c|c|c|c|}
\hline & $3 \%$ ODI $<5 / h$ & $3 \%$ ODI $\geq 5 / h$ & $\mathrm{p}$ value \\
\hline $\mathrm{N}$ & 62 & 26 & \\
\hline Age years, mean $\pm \mathrm{SD}$ & $31.4 \pm 4.6$ & $29.7 \pm 4.8$ & 0.11 \\
\hline Primipara, n (\%) & $28(45.9)$ & $12(46.2)$ & 1 \\
\hline \multicolumn{4}{|l|}{ Body mass index } \\
\hline Pre-pregnancy $\mathrm{kg} / \mathrm{m}^{2}$, median (IQR) & $20.0(18.6-21.6)$ & $21.5(20.2-22.8)$ & 0.03 \\
\hline Second trimester $\mathrm{kg} / \mathrm{m}^{2}$, median (IQR) & $22.2(20.9-23.9)$ & $23.8(22.7-25.3)$ & 0.01 \\
\hline Third trimester $\mathrm{kg} / \mathrm{m}^{2}$, median (IQR) & $23.6(22.4-25.5)$ & $26.3(24.2-27.4)$ & 0.004 \\
\hline \multicolumn{4}{|l|}{ Weight gain } \\
\hline From pre-pregnancy kg, median (IQR) & $10.0(8.0-13.1)$ & $10.8(9.5-13.6)$ & 0.22 \\
\hline From second trimester $\mathrm{kg}$, median (IQR) & $3.9(2.5-4.4)$ & $4.1(3.1-5.0)$ & 0.08 \\
\hline \multicolumn{4}{|l|}{ Rate of weight gain } \\
\hline From pre-pregnancy \%, median (IQR) & $18.1(13.8-23.4)$ & $20.1(18.5-21.7)$ & 0.12 \\
\hline From second trimester \%, median (IQR) & $6.6(4.5-8.5)$ & $6.8(5.8-7.9)$ & 0.27 \\
\hline
\end{tabular}

IQR, interquartile range; ODI, oxygen desaturation index; SD, standard deviation.

Table 3. Comparison of sleep problems between 3\% ODI < 5/h group and 3\% ODI $\geq 5 /$ h group at the third trimester of pregnancy

\begin{tabular}{|c|c|c|c|}
\hline & $3 \%$ ODI $<5 / h$ & $3 \%$ ODI $\geq 5 / h$ & $\mathrm{p}$ value \\
\hline $\bar{N}$ & 62 & 26 & \\
\hline \multicolumn{4}{|l|}{ PSQI } \\
\hline C1凸sleep quality $\geq 2, \mathrm{n}(\%)$ & $31(50.0)$ & $20(76.9)$ & 0.03 \\
\hline C2\sleep latency $\geq 2^{1)}, \mathrm{n}(\%)$ & $28(45.2)$ & $15(57.7)$ & 0.35 \\
\hline C3־sleep duration $\geq 2^{2)}, \mathrm{n}(\%)$ & $19(30.6)$ & $11(42.3)$ & 0.33 \\
\hline 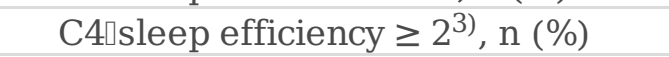 & $6(9.7)$ & $6(23.1)$ & 0.17 \\
\hline C5 $\square$ sleep disturbance $\geq 2, \mathrm{n}(\%)$ & $29(46.8)$ & $20(76.9)$ & 0.01 \\
\hline C6』hypnotic use $\geq 2^{4)}, \mathrm{n}(\%)$ & $0(0.0)$ & $1(3.8)$ & 0.30 \\
\hline C7】daytime dysfunction $\geq 2, \mathrm{n}(\%)$ & $6(9.7)$ & $2(7.7)$ & 1 \\
\hline Global score, n (\%) & $35(56.5)$ & $20(76.9)$ & 0.09 \\
\hline \multicolumn{4}{|l|}{ ISI } \\
\hline Mild to severe DIS, n (\%) & $48(77.4)$ & $23(88.5)$ & 0.38 \\
\hline Moderate to severe DIS, n (\%) & $23(37.1)$ & $14(53.8)$ & 0.16 \\
\hline Mild to severe DMS, n (\%) & $46(74.2)$ & $21(80.8)$ & 0.59 \\
\hline Moderate to severe DMS, $\mathrm{n}(\%)$ & $21(33.9)$ & $19(73.1)$ & 0.001 \\
\hline Mild to severe DIMS, n (\%) & $56(90.3)$ & $24(92.3)$ & 1 \\
\hline Moderate to severe DIMS, n (\%) & $29(46.8)$ & $20(76.9)$ & 0.01 \\
\hline Global score $\geq 10, \mathrm{n}(\%)$ & $32(51.6)$ & $15(57.7)$ & 0.65 \\
\hline $\mathrm{ESS} \geq 11, \mathrm{n}(\%)$ & $28(45.2)$ & $15(57.7)$ & 0.35 \\
\hline RLS/WED, n (\%) & $6(9.7)$ & $2(7.7)$ & 1 \\
\hline
\end{tabular}

1) Sleep latency $\geq 31 \mathrm{~min}$ and the presence of difficulty initiating sleep. ${ }^{2)}$ Total sleep time $<6$ hours. ${ }^{3)}$ Sleep Efficiency <85\%. ${ }^{4)}$ More than one time. DIS, difficulty initiating sleep; DISM, difficulty initiating and/or maintaining sleep; DMS, difficulty maintaining sleep; ESS, Epworth Sleepiness Scale; ISI, Insomnia Severity Index; ODI, oxygen desaturation index; PSQI, Pittsburgh Sleep Quality Index global score; RLS/WED, restless legs syndrome/Willis-Ekbom disease. 
Table $4 \llbracket$ Comparison of sleep problems between ESS $<11$ group and ESS $\geq 11$ group at the third trimester of pregnancy

\begin{tabular}{|c|c|c|c|}
\hline & ESS $<11$ & $\mathrm{ESS} \geq 11$ & $\mathrm{p}$ value \\
\hline $\mathrm{N}$ & 45 & 43 & \\
\hline \multicolumn{4}{|l|}{ PSQI } \\
\hline C1』sleep quality $\geq 2, \mathrm{n}(\%)$ & $21(46.7)$ & $30(69.8)$ & 0.03 \\
\hline C2】sleep latency $\geq 2^{1)}, \mathrm{n}(\%)$ & $17(37.8)$ & $26(60.5)$ & 0.05 \\
\hline C3\sleep duration $\geq 2^{2)}$, n (\%) & $9(20.0)$ & $21(48.8)$ & 0.007 \\
\hline C4\sleep efficiency $\geq 2^{3)}, \mathrm{n}(\%)$ & $4(8.9)$ & $8(18.6)$ & 0.22 \\
\hline C5ロsleep disturbance $\geq 2, \mathrm{n}(\%)$ & $18(40.0)$ & $31(72.1)$ & 0.003 \\
\hline C6ロhypnotic use $\geq 2^{4)}$, n (\%) & $0(0.0)$ & $1(2.3)$ & 0.49 \\
\hline C7ロdaytime dysfunction $\geq 2, \mathrm{n}(\%)$ & $1(2.2)$ & $7(16.3)$ & 0.03 \\
\hline Global score, n (\%) & $21(46.7)$ & $34(79.1)$ & 0.002 \\
\hline \multicolumn{4}{|l|}{ ISI } \\
\hline Mild to severe DIS, n (\%) & $32(71.1)$ & 39 (90.7) & 0.03 \\
\hline Moderate to severe DIS, n (\%) & $13(28.9)$ & $24(55.8)$ & 0.02 \\
\hline Mild to severe DMS, n (\%) & $29(64.4)$ & $38(88.4)$ & 0.01 \\
\hline Moderate to severe DMS, n (\%) & $13(28.9)$ & $27(62.8)$ & 0.003 \\
\hline Mild to severe DIMS, n (\%) & $39(86.7)$ & $41(95.3)$ & 0.27 \\
\hline Moderate to severe DIMS, n (\%) & $16(35.6)$ & $33(76.7)$ & $<0.001$ \\
\hline Global score $\geq 10, \mathrm{n}(\%)$ & $4(8.9)$ & $43(100.0)$ & $<0.001$ \\
\hline RLS/WED, n (\%) & $2(4.4)$ & $6(14.0)$ & 0.15 \\
\hline $3 \%$ ODI $\geq 5, n(\%)$ & $11(24.4)$ & $15(34.9)$ & 0.35 \\
\hline
\end{tabular}

1) Sleep latency $\geq 31 \mathrm{~min}$ and the presence of difficulty initiating sleep. ${ }^{2)}$ Total sleep time $<6$ hours. ${ }^{3)}$ Sleep Efficiency <85\%. ${ }^{4)}$ More than one time. DIS, difficulty initiating sleep; DISM, difficulty initiating and/or maintaining sleep; DMS, difficulty maintaining sleep; ESS, Epworth Sleepiness Scale; ISI, Insomnia Severity Index; ODI, oxygen desaturation index; PSQI, Pittsburgh Sleep Quality Index global score; RLS/WED, restless legs syndrome/Willis-Ekbom disease.

Table 5. Logistic regression analysis for daytime sleepiness at the third trimester of pregnancy

\begin{tabular}{lcc}
\hline & $\begin{array}{c}\text { Unadjusted odds ratio } \\
\text { (95\% confidence interval) }\end{array}$ & $\begin{array}{c}\text { Adjusted odds ratio† } \\
\text { (95\% confidence interval) }\end{array}$ \\
\hline $\begin{array}{l}\text { Total sleep time } \\
\quad \text { 6 hours (reference) }\end{array}$ & 1 & 1 \\
$\quad<6$ hours & $3.82(1.49-9.81)$ & $3.25(1.16-9.10)$ \\
$\begin{array}{l}\text { Difficulty maintain sleep } \\
\text { None to mild (reference) } \\
\quad \text { Moderate to severe }\end{array}$ & 1 & 1 \\
$\begin{array}{l}3 \% \text { Oxygen desaturation index } \\
<5 / \text { h (reference) }\end{array}$ & $4.15(1.70-10.10)$ & $4.74(1.60-14.00)$ \\
$\geq 5 / h$ & 1 & 1 \\
& $1.66(0.66-4.18)$ & $0.90(0.28-2.89)$ \\
\hline
\end{tabular}

†Adjusted for age and body mass index. 
Table 6. Sleep disordered breathing at the third trimester of pregnancy and delivery outcomes 


\begin{tabular}{|c|c|c|c|}
\hline & $3 \%$ ODI $<5 / h$ & $3 \%$ ODI $\geq 5 / h$ & $\mathrm{p}$ value \\
\hline $\mathrm{N}$ & $61 *$ & 26 & \\
\hline Gestational age months, median (IQR) & $40.0(39.6-40.3)$ & $39.7(39.2-40.2)$ & 0.48 \\
\hline Duration of birth hours, median (IQR) & $5.9(4.0-10.3)$ & $6.1(4.0-9.1)$ & 0.93 \\
\hline \multicolumn{4}{|l|}{ Type of birth } \\
\hline Vaginal delivery, $\mathrm{n}(\%)$ & $57(93.4)$ & $22(84.6)$ & 0.35 \\
\hline Cesarean section, $\mathrm{n}(\%)$ & $4(6.6)$ & $4(15.4)$ & \\
\hline Labor induction, n (\%) & $8(13.1)$ & $3(11.5)$ & 0.84 \\
\hline Episiotomy, n (\%) & 0 & $1(3.8)$ & 0.13 \\
\hline Perineal laceration, $\mathrm{n}(\%)$ & $40(65.6)$ & $14(53.8)$ & 0.31 \\
\hline Volume of blood loss ml, median (IQR) & $580(370-800)$ & $735(460-910)$ & 0.27 \\
\hline Use of oxytocic, $\mathrm{n}(\%)$ & $37(60.7)$ & $16(61.5)$ & 0.94 \\
\hline \multicolumn{4}{|l|}{ Infant's condition } \\
\hline Alive, n (\%) & $60(96.8)$ & $26(100.0)$ & 1 \\
\hline Stillbirth, n (\%) & $1(1.6)$ & 0 & \\
\hline Weight of infant g, median (IQR) & $3176(2922-3404)$ & $3145(2914-3445)$ & 0.51 \\
\hline Height of infant $\mathrm{cm}$, median (IQR) & $49.0(48.0-50.2)$ & $49.0(47.5-49.5)$ & 0.51 \\
\hline \multicolumn{4}{|l|}{ Apgar score } \\
\hline $1 \min \leq 6, \mathrm{n}(\%)$ & $1(1.6)$ & $2(7.7)$ & 0.15 \\
\hline $5 \min \leq 6, \mathrm{n}(\%)$ & $1(1.6)$ & $1(3.8)$ & 0.52 \\
\hline
\end{tabular}




\begin{tabular}{|c|c|c|c|}
\hline pH, median (IQR) & 7.32 (7.28-7.37) & $7.36(7.32-7.41)$ & 0.06 \\
\hline$<7.2, \mathrm{n}(\%)$ & $3(5.0)$ & $1(3.8)$ & 1 \\
\hline$\geq 7.2, \mathrm{n}(\%)$ & $57(95.0)$ & $25(96.2)$ & \\
\hline $\mathrm{PaCO}_{2}$ mmHg, median (IQR) & $34.8(26.8-41.3)$ & $29.5(22.8-32.8)$ & 0.15 \\
\hline$<32 \mathrm{mmHg}, \mathrm{n}(\%)$ & $24(40.0)$ & $16(61.5)$ & 0.14 \\
\hline 32-68 mmHg, n (\%) & $35(58.3)$ & $10(38.5)$ & \\
\hline > 68 mmHg, n (\%) & $1(1.7)$ & 0 & \\
\hline
\end{tabular}

*Uncertain one woman. IQR, interquartile range; ODI, oxygen desaturation index.

Figures 


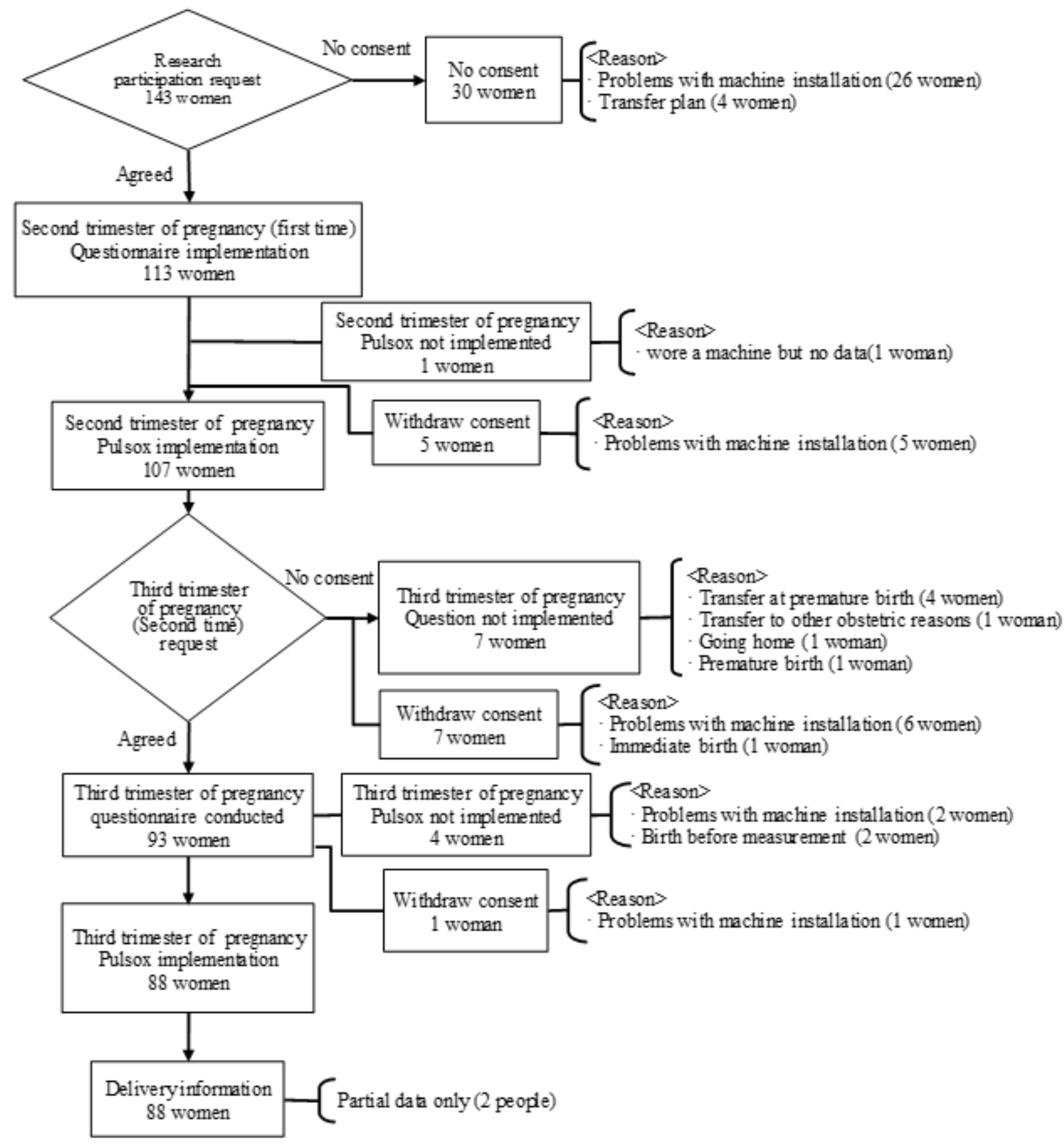

Figure 1

Data collection algorithm

\section{Supplementary Files}

This is a list of supplementary files associated with this preprint. Click to download.

- Supplementarymaterial.pdf 
- data.csv

Page 19/19 